\author{
Historical Studies in Education / Revue d'histoire de l'éducation \\ SPECIAL ISSUE / NUMÉRO SPÉCIAL \\ Education North of 60 / Éducation au nord du 60e
}

\title{
North of 60: Some Methodological Considerations for Educational Historians
}

\section{Heather E. McGregor}

Knowing where to look for historical sources and what questions to ask of them, such as the questions outlined in the Introduction to this Special Issue, is only part of conducting research North of 60 . Historians also need to ask themselves about how to approach inquiry into the territorial educational past. The North is a place where much of what is taken for granted elsewhere about research into the past (or any subject, for that matter) may be questioned, or must be modified.

A group of Canada's most experienced northern historians, of whom there are relatively few, issued a call in 2001 to "lessen the distance" between academic historians and northern peoples. ${ }^{1}$ This is certainly important in geographic terms, but can also be applied figuratively to conceptual design, choice of sources, and historical interpretation. For example, Mary-Ellen Kelm notes significant historiographic contributions resulting from the near-necessity to conduct oral history as part of documenting First Nations' histories in the territories, including, most prominently, Julie Cruikshank's research in the Yukon. ${ }^{2}$ She also points out that interdisciplinarity (among history, anthropology, archaeology, medicine, geography, and auto-ethnology) has been a strong feature of northern history, resulting "from its desire to grapple with complexity."3 Shelagh Grant outlined some of the "challenges and rewards" of Inuit historiography, calling on academic historians to "familiarize themselves with the Arctic and its people before contemplating writing" - and by this she meant "experience in the field," with all its associated complicating factors. ${ }^{4}$

Whereas dialogue on northern historical methodology is not an entirely new conversation, I want to illuminate some specific dimensions drawing from recent scholarship on research with Indigenous communities, as well as on sources relevant to histories of education in particular. I do not presume to suggest that I can prepare historians adequately to engage with First Peoples' histories, nor do I speak on behalf of those communities. There are no fail-safe tricks at hand, and the work of determining what is appropriate, relevant, and do-able must be responsive to how each research project is situated in time, space, and relationships. It is important, however, to recognize what can be gleaned from existing literature about both the possibilities and constraints of 
working differently within these parameters. For example, elsewhere I have explored the field of ethnohistory in relation to the history of education, bringing the methodological commitments of that approach together in conversation with Indigenous critiques of the discipline of history. ${ }^{5}$ In work such as this, it is particularly important to maintain openness to colleagues, including Indigenous scholars, working in faculties of education, Native studies, or anthropology. ${ }^{6}$ Echoing Kelm's comment above, there is little room for disciplinary or methodological rigidity in this context.

In what follows, I discuss five overlapping and interconnected categories of methodological considerations in pursuing histories of education in the territorial North: general issues with, and legacies of, research; translating Indigenous ways of knowing, being, and doing into the conventions of academia; accommodating locally and culturally responsive practices of engaging with the past; ethical considerations; and, logistics. All of these considerations are predicated on the assumption that, in one way or another, historians will engage in a conversation or relationship with territorial residents before they start, during their work, and when it is complete. They may do so by consulting with potential partners, listening carefully when they visit the North, collecting sources, conducting oral histories, discussing results with participants before finalization, disseminating their work to Northerners, or by other means.

\section{General Issues with, and Legacies of, Research}

While historians, and particularly educational historians, may not have been - to date - frequently "seen" around the territories, other researchers have. Members of northern communities may have preconceptions about who these researchers are, and what they do. Some historians may balk at being lumped in with scientists (or even social scientists!), but we need to remember that community members may see people from the university as cut from the same cloth. ${ }^{7}$ There have been negative and damaging impressions left on individuals, families, schools, and communities by researchers; indeed, such things continue to occur. According to a 2013 report by Inuit Tapiriit Kanatami's National Committee on Education about development of an Inuit education research agenda, "We heard the words 'intrusive' and 'belittling' to describe research projects that were viewed as 'de-humanizing' — research projects that too often were 'about' Inuit and not conducted 'with' Inuit, or answer questions important to Inuit." ${ }^{\prime}$ Historians should be aware that community members in the territories may approach them and their work with some scepticism. It may be important to listen and learn about the history of research, as well as the history of schooling, in a particular region, in order to be responsive to those we encounter or ask to participate in research.?

Questions of identity politics, representation, and voice are ubiquitous in territorial and Indigenous research. ${ }^{10}$ This need not paralyze prospective historians, but warrants thoughtful reflection and willingness to answer questions such as: Who can speak for whom? How well are you positioned to do certain kinds of research? How do you know what you know? Who invited you here and what will you give back? What good does your research do, now and in the future? What does shared authority in history 
research look like? If you do not do this work, who will-meaning, might the work not be done at all, or might it be done by someone with less awareness of northern community interests? Should researchers ever push to convince a community that research questions they originally did not support might turn out to be meaningful or important? These are questions that other researchers, such as ethnographers, have been expected to answer, but historians may still not be well versed in such considerations.

Finally, regarding research issues in general, I suggest that historians think about whether partnership is something they value in conducting research into the past, and if so, on whose terms a partnership is initiated and pursued. ${ }^{11}$ In some cases this may mean that a research question about the past comes from the community and an historian is asked to investigate it with some degree of autonomy. Indeed, this may be because members of a community or organization do not have time, capacity, or will to participate in the research themselves - but nevertheless value it. In other cases an historian may be expected to conduct participatory and community-driven research into historical events. They may be asked to partner with, train, or mentor Indigenous researchers who could conduct similar projects in the future. Another approach might be for the historian to write independently and then go to the community for feedback, validation, fact-checking, and dissemination of the findings in ways that are relevant to local people. Some historians may be Indigenous or, like several of the authors in this Special Issue, draw on long residency and participation in the institutions and places under study. Affiliation with northern communities, and how that serves to imbue research questions with territorial perspectives, takes different forms. Also, as discussed in the Introduction, historians may open up stories from the territorial North to southern Canadian audiences, help them understand their northern neighbours, or shed a different light on national views with the addition of northern perspectives. One approach is not better than another, and one formula will not work across the board. It is the communities and affected parties - along with the specific skills and interests of the historian - that should determine what research partnerships look like. I hope historians will be open to those possibilities.

\section{Translating Indigenous Ways of Knowing, Being, and Doing into the Conventions of Academia}

Establishing respectful and responsible relationships with people in the territories almost guarantees that an historian will have to grapple with this second category of issues. The historiographical implications of working with ideas generated by people working within, or in relation to, Indigenous epistemologies and ontologies are exceedingly complex, as Julie Cruikshank's work has demonstrated. ${ }^{12}$ Robin Jarvis Brownlie asserts that a large part of the reluctance in academic history to integrate Indigenous knowledge can be attributed to an attachment to rational foundationalism and normative epistemologies connected to Euro-western and Enlightenment frameworks. ${ }^{13}$ And as Michael Marker has pointed out, history classrooms have usually been particularly uncomfortable places for Indigenous students due to the common refusal to acknowledge Indigenous interpretations of the past. ${ }^{14}$ Perhaps it is 
partly because of this legacy that there are few Indigenous adults who have felt welcome to become historians. ${ }^{15}$

One of the ways in which differing — and potentially conflicting - interpretive paradigms reveal themselves is in the use of, and criteria for, credible sources. For example, how should historians use the observations of explorers, anthropologists, Hudson's Bay Company staff members, or representatives of the state such as RCMP members or nurses, to represent or interpret the experiences of First Peoples in the past? Should we believe the statement made by a person working for the state that Indigenous parents gave permission for their children to go to residential schools? It is most likely there will be no other documentary sources - what then? While in some contexts the memories of individuals might be superseded by the administrative or government record, in Inuit society, for example, individuals' memories and differing truths are held in high regard and are not typically questioned or considered invalid when shown to be inconsistent with the official record. ${ }^{16}$

\section{Locally and Culturally Responsive Practices of Engaging with the Past}

The third category, deeply intertwined with the first two, is attending to how an historian might best accommodate locally and culturally responsive practices and protocols by which Northerners engage with knowledge about the past. ${ }^{17}$ Again, few generalizations can be made, as Inuit, Métis, and First Nations have different ways of documenting, performing, or sharing historical knowledge. I suggest that non-Indigenous Northerners may also be consulted about community expectations for inquiry into the past, as they can sometimes communicate or translate community expectations effectively for individuals who originate outside the territories. Historians may need to learn the cultural and linguistic expectations and practices that surround oral history as it was traditionally practised, and as it has come to be practised now. This may involve protocols and relationship building necessary for working with Indigenous Elders and accessing their traditional knowledge or memories. ${ }^{18}$ Working with Elders or using oral testimony that was recorded in the past almost inevitably involves linguistic translation, which can itself become a challenge in producing highquality interpretations and representations - not to mention the expense in time and money. ${ }^{19}$ Indeed, even when English is used, it is used variously and variably, and one must take great care to learn how to listen and make meaning if one has not been educated or raised in that culture. Some potential informants may feel they are not the best expert on the history in question and recommend consultation with another Elder, or someone who has since left the community. ${ }^{20}$ Showing respect for such community-driven views of how history should be done is important for establishing reciprocal relationships with territorial residents.

\section{Ethical Considerations}

The historiographical or methodological decisions we make are inextricable from ethical considerations, and here I understand ethics to mean something beyond 
the bare minimum required by review boards, and closer to the sense advocated by Indigenous communities. ${ }^{21}$ However, in the territories there are additional formal steps to consider because of the necessity to conduct consultation in securing a research licence, and other obligations associated with licences. In Nunavut and the Northwest Territories, if social science research of any kind involves interviews or participation (i.e., anything beyond the use of public documents), it is necessary to apply for a research licence. ${ }^{22}$ Even for just one interview, an historian must seek permission. And frequently, to secure the research licence, it is necessary to submit evidence of having institutional ethics approval from the university with which one is affiliated. So while historians may not be accustomed to being asked, for example, "what are the risks associated with participating in your research," they must at least begin to consider these questions when securing permission to proceed. In many cases communities may not provide specific feedback or comments to researchers following a review of their plans and intentions, but taking this process seriously - rather than seeing it as a hoop-jumping exercise — is worthwhile because it should prompt one to engage with all the considerations listed thus far.

I encountered a situation where the Nunavut Research Institute advised me that the type of research I was conducting did not require a licence, and yet an interested party in Nunavut did not feel comfortable with my work without one, so I was stuck in a grey zone between jurisdictions and judgements of appropriate permissions. ${ }^{23}$ Ethical considerations also do not end after "clearing" research ethics boards or licensing processes, but rather warrant ongoing consideration as and when methodological approaches are undertaken or change during the inquiry. Elsewhere I explain significant changes to the design of my doctoral research methodology when the educational history project I originally proposed and was licenced for - predicated on numerous interviews and a focus group - no longer suited the political and administrative context of my work. ${ }^{24}$ In that case, it felt more ethical to reduce the number of participants, and consequently change the story that was told, than to negotiate potential risks or responsibilities associated with a delicate community balance. In other words, researchers may sometimes need to pull back from engagement in order to honour the ability and willingness of communities to support research at different times and in different places.

\section{Logistics}

Lastly, the dreaded issue of logistics. ${ }^{25}$ Many historians do not consider going North to begin with because of the distance, costs, and time associated with travel. Certainly some information and details about archival materials can be accessed from southern Canada but, for the most part, historians need to be on site and see the sources, whether they be people or documents. Indeed, sources one might never have expected can arise in visits to the territories — such as a long conversation on a plane ride to get there, or a box found on the top shelf in a library while looking for something else. How does one secure the support to get to the North for all the reasons and occasions it may be necessary: to build research relationships or do preliminary consultations, 
to track down participants or sources, to spend time learning about the context, to review the sources carefully, to secure input into the analysis and to disseminate the findings? ${ }^{26}$ With travel easily costing double what it would to fly across southern Canada, as well as the expenses when one arrives, these implications are significant. I was recently in Rankin Inlet for a workshop and ended up having three extra days of expenses due to bad weather delays. For large institutions or northern organizations these extra costs may be absorbed, but for graduate students or researchers operating on a stretched budget they can be prohibitive.

Securing research funding from sources such as the Social Sciences and Humanities Research Council of Canada involves mediating between the priorities, expectations, and timelines set out by the funder and those set out by "the North" — which can differ substantially. Historians will have to be creative and persuasive in seeking the necessary funding to conduct their projects well; drawing on local resources may be the best way to ensure money is being spent effectively. Technology makes it increasingly possible to share sources digitally, but more investment is needed by the organizations holding collections, as well as individual researchers who make use of records and could do more to share them. This is all the more reason to make a long-term commitment to territorial research, which may diminish the stress associated with establishing and maintaining the logistics associated with doing history North of 60 .

\section{Conclusions}

I would like to end with a list of the concomitant rewards of northern educational history, but as many historians likely know, rewards are never guaranteed in our inquiries into the past - nor should they be. A northern teacher has told me that my work is "pretty dry." But, I have also spoken with northern teachers who have told me that something in my work resonated deeply with them. Those are the most rewarding moments I have experienced. As is evident from my approach here, I advocate that benefits ought to accrue to Northerners as a result of historical inquiry into their educational past. This is certainly the case for those historians who expect to receive accreditation (like graduate students), funding, merit on their publication record, royalties from publishing, or academic prestige from their work. ${ }^{27}$ These are the things historians must grapple with, part of the privilege and responsibility of doing this work, as well as the challenge inherent in it.

Educational historians might do well to begin reaching out to one another and creating a dialogue about what kinds of expectations communities, schools, research licencing bodies, and institutions have for what constitutes ethical relationships in research about the past. Independent scholars, public historians, community- or institutionally-appointed researchers located in the territories, or those who pursue research under other circumstances — and from other disciplines - may have much to teach academic researchers about negotiating these methodological complexities. And much could be offered in return. Sharing questions and experiences should be a place to start, so that we do not re-make the same mistakes as researchers in the past, or try to re-invent the wheel. ${ }^{28}$ The authors published here all continue to look 
for suggestions and to learn more about pursuing useful and creative research into the past that responds to the context in which it is situated. This Special Issue ends, then, with an invitation to territorial educational historians: let's create a community, pursue an inclusive conversation about these topics, and grow together.

\section{Notes}

1 See Kerry Abel and Ken S. Coates, eds., Northern Visions: New Perspectives on the North in Canadian History, (Broadview Press: Peterborough, 2001), esp. Bill Waiser, "A Very Long Journey: Distance and Northern History," 37-44.

2 Mary-Ellen Kelm, "Change, Continuity, Renewal: Lessons from a Decade of Historiography on the First Nations of the Territorial North," in Northern Visions, ed. Abel and Coates, 77-90; see also note 12 below.

3 Ibid., 89.

4 Shelagh D. Grant, "Inuit History in the Next Millennium: Challenges and Rewards," in Northern Visions, ed. Abel and Coates, 99.

5 Heather E. McGregor, "Exploring Ethnohistory and Indigenous Scholarship: What is the Relevance to Educational Historians?" History of Education 43, 4 (2014): 431-49.

6 See, for example, Michael Marker, "Review Essay: Ethnohistory and Indigenous Education: A Moment of Uncertainty," History of Education 29, 1 (2000): 79-85.

7 For example, as someone affiliated with UBC (during my doctorate) I have been told by a northern resident, "Oh, you probably know this other person from UBC who is doing research in my community - I forget their name." With 4,600 faculty members and 50,000 students at the Vancouver campus, the likelihood of me knowing the other researcher is low, even when speaking about the number of individuals involved in Nunavut research. My point is not that the resident is unaware of the size of UBC, but that I might be inaccurately associated with the other researcher, and the way community members were responding to me could very well have been coloured by their previous experience. Institutional or disciplinary affiliations may mean a great deal, or very little, depending on local community experiences with those in question, and this is important to be aware of.

8 Mary Simon, "Chairperson's Message," Future Directions in Research in Inuit Education: A report prepared from the proceedings from the $1^{\text {st }}$ Forum on Research in Inuit Education (Ottawa: Amaujaq National Centre for Inuit Education, Inuit Tapiriit Kanatami, 2013).

9 For more on the Inuit education research forum, see Heather E. McGregor, "Developing an education research agenda in Nunavut: A Northerner's point of view," Northern Public Affairs 2, Special Issue (2014): 77-79.

10 A useful discussion of such considerations can be found in Sophie McCall, First Person Plural: Aboriginal Storytelling and the Ethics of Collaborative Authorship (Vancouver: UBC Press, 2011). See esp. chap. 2, 43-75, dealing with the NWT.

11 See for example Pamela Stern and Lisa Stevenson, Critical Inuit Studies: An Anthology of Contemporary Arctic Ethnography (Lincoln and London: University of Nebraska Press, 2006), esp. chap. 3, 54-70; Shari Gearhead and Jamal Shirley, "Challenges in community-research relationships: Learning from natural science in Nunavut," Arctic 60, 1 (2007): 62-74; Bryan S. R. Grimwood, Nancy C. Doubleday, Gita J. Ljubicic, Shawn G. Donaldson, and Sylvie Blangy, "Engaged acclimatization: Towards responsible community-based participatory research in Nunavut," The Canadian Geographer 56, 2 (2012): 211-30; and, Sarah de Leeuw, Emilie S. Cameron, and Margo L. Greenwood, "Participatory and community-based research, Indigenous geographies, and the spaces of friendship: A critical engagement," The Canadian Geographer 56, 2 (2012): 180-94. 
12 Julie Cruikshank, "Oral History, Narrative Strategies, and Native American Historiography: Perspectives from the Yukon Territory, Canada," in Clearing a Path: Theorizing the Past in Native American Studies, ed. Nancy Shoemaker (New York: Routledge, 2002), 3-27; Julie Cruikshank, Do Glaciers Listen? Local Knowledge, Colonial Encounters and Social Imagination (Vancouver: UBC Press, 2005); Julie Cruikshank, The Social Life of Stories: Narrative and Knowledge in the Yukon Territory (Vancouver: UBC Press, 1998).

13 Robin Jarvis Brownlie, "First Nations Perspectives and Historical Thinking in Canada," in First Nations, First Thoughts: The Impact of Indigenous Thought in Canada, ed. Annis May Timpson (Vancouver: UBC Press, 2009), 21-50.

14 Michael Marker, "Teaching History from an Indigenous Perspective: Four Winding Paths Up the Mountain," in New Possibilities for the Past: Shaping History Education in Canada, ed. Penney Clark (Vancouver: UBC Press, 2011), 97-112.

15 At any annual meeting of the Canadian Historical Association, for example, it is noticeable that there are few Indigenous historians present.

16 This point is very well demonstrated in Joe MacDonald and Charlotte DeWolff (producers), and Ole Gjerstad and Joelie Sanguya (directors), Qimmit: A Clash of Two Truths, Video/DVD (Ottawa: Piksuk Media; and National Film Board of Canada, 2010). See also Qikiqtani Truth Commission [QTC], QTC Final Report: Achieving Saimaqatigiingniq (Iqaluit: Qikiqtani Inuit Association, 2010); Qikiqtani Truth Commission [QTC], Qikiqtani Truth Commission: Thematic Reports and Special Studies, 1950-1975 (Iqaluit: Inhabit Media, 2013).

17 For example, Lisa Stevenson elaborates on how Inuit youth are encouraged - with urgency - by Elders to remember their language, values, and traditional ways of life as a result of the historical, political, and cultural conditions of Nunavut. See Lisa Stevenson, "The Ethical Injunction to Remember," in Critical Inuit Studies: An Anthology of Contemporary Arctic Ethnography, ed. Pamela Stern and Lisa Stevenson (Lincoln and London: University of Nebraska Press, 2006), 169-83.

18 I documented my own encounter with this issue when I turned to transcripts of government meetings as sources of Elder knowledge because I did not feel I could (at that time) enter appropriate relationships with Elders in a particular Nunavut community. See Heather E. McGregor, Inuit Education and Schools in the Eastern Arctic (Vancouver: UBC Press, 2010), xi-xiv.

19 For discussions of the deep ethical and political implications of translation issues, see Emilie Cameron, Rebecca Mearns, and Janet Tamalik McGrath, "Translating Climate Change: Adaptation, Resilience, and Climate Politics in Nunavut, Canada," Annals of the Association of American Geographers (2015): 1-10; and, Janet Tamalik McGrath, "Isumaksaqsiurutigijakka: Conversations with Aupilaarjuk Towards a Theory of Inuktitut Knowledge Renewal” (PhD diss., Canadian Studies, Carleton University, 2011).

20 As in small towns elsewhere, Northerners often recommend colleagues and acquaintances who hold expertise in a particular subject or were considered the community "point-person" for a specific program. Unlike the inhabitants of other small towns, however, if those individuals were Euro-Canadian teachers or administrators who worked in territorial schools, they are likely to be now scattered across the country and have varying degrees of sustained contact with the North.

21 For resources on northern ethical guidelines, see Scott Nickels, Jamal Shirley, and Gita Laidler, eds., Negotiating Research Relationships with Inuit Communities: A Guide for Researchers (Ottawa and Iqaluit: Inuit Tapiriit Kanatami and Nunavut Research Institute, 2007); Association for Canadian Universities for Northern Studies, Ethical Principles for the Conduct of Research in the North (Ottawa: ACUNS, 2003). 
22 See www.nri.nu.ca (accessed 13 February 2015) and www.nwtresearch.com (accessed 13 February 2015). For information on the Yukon see www.yukoncollege.yk.ca/research (accessed 13 February 2015). There are of course certain restrictions on using archival documents that identify and reveal personal information about people in recent periods.

23 McGregor, Inuit Education, xii-xiv.

24 Heather E. McGregor, "Decolonizing the Nunavut School System: Stories in a River of Time" (PhD diss., University of British Columbia, 2015).

25 Shelagh Grant also touches on this issue in "Inuit History in the Next Millenium," 99-104.

26 One possible source of support, especially for graduate students, is the Association of Canadian Universities for Northern Studies: http://www.acuns.ca (accessed 13 February 2015), though it is evident from their website that scholars in the humanities are less well represented in Arctic research funding opportunities and may need to drum up additional support.

27 It is worth mentioning that while graduate students ought to consider these issues as much as those who are farther advanced in their research careers, they often require different supports and accommodations. For example, they negotiate limitations in income and funding, length of program, supervisory oversight, research training/ experience, and have had less time to develop research relationships.

28 And on this point, I would like to acknowledge with gratitude those with whom I have been in conversation on many of the issues outlined here: Cathy McGregor, Michael Marker, Sheena Kennedy Dalseg, Wyn Millar and many other scholars and community members from whom I have learned. 